\title{
Maintaining optimism in adversity: physicians leading innovation, education and responsible care delivery
}

Welcome to the spring edition of Clinical Medicine. As I write this we are all continuing to work against significant adversity in the NHS; we are now in March (April by the time you read this) but there is little sign of the hare; the green shoots of spring are firmly stalled by the snowdrifts and Siberian freeze, and alas there is little apparent optimism in the workplace. So, against this backdrop how do I present this month's offering in Clin Med?

I am by nature an optimist and, as with every month I write this editorial, I look to pull together the positives of what this journal offers to you, the readership, in supporting our endeavours in delivering care to patients. I also attempt to ground this editorial in a wider view of current healthcare issues.

Despite the negative ramifications of the Bawa-Garba case and the genuine shockwaves that have been wrought by the GMC on our profession, I believe we must continue to reflect on our practice, acknowledge our knowledge deficits and endeavour to remain clinically up-to-date, in a field that continues to develop at an astonishing rate. Having just read an edition of the MIT Technology Review on a trans-Atlantic flight, it is clear to me that the broader world of medicinal science remains a positive, visionary, vibrant, dynamic and optimistic place that reaches far beyond the trials and tribulations of our daily clinical work. It is a visionary world that we must not lose sight of as clinicians in these chastening times and we must maintain an optimism for those we care for.

I try and look for golden threads in each edition of Clin Med; those issues that allow a cogent message to be drawn from the diverse offerings we bring to you. In this edition I feel those threads are threefold: firstly, about us maintaining and developing our knowledge to deliver high-quality care; secondly, being guardians of the resources that we have responsibility for; and finally the need to take responsibility for developing our clinical care against a backdrop of relentless funding and staffing pressures.

Taking the former point first, the CME in this edition focuses on the latest evidence base for the management of infections, with erudite and informative articles that cover both localised and systemic presentations. Alongside this there is a contemporaneous review on modern heart failure management, ${ }^{1}$ which offers concise and practical guidance.

The original research in this edition speaks to the second point about resource management and critical appraisal of how we practice, with analytical manuscripts describing service provision in cardiology ${ }^{2}$ and gastroenterology. ${ }^{3}$ These offer us evidence to inform the delivery of high-quality care whilst at the same time relieving pressure on emergency departments and acute admissions units. While much of the pressure on the system in the winter crises has been blamed on sicker patients and naive centralist solutions moving care to the community, we should not discard all attempt to appropriately rationalise inpatient care, in scarce hospital beds, where possible. This edition also offers an interesting international focus on developing medical care in sub-Saharan Africa with a simple risk assessment model that may allow for a quicker and simpler way to assess malnutrition and the associated morbidity and mortality that accompanies it. ${ }^{4}$

Finally, I note with some cautious optimism that Sarah Wollaston, as chair of the Health Select Committee, is continuing to lobby for an all-party debate on the future funding of health and social care. As a GP and an MP, I believe she truly understands the issues we face, and despite numerous rebuttals to date, she continues to echo the view of the RCP and other colleges that we, the workforce, can only do so much on our own to deliver twentyfirst century healthcare, and that we need a sustainable political agreement on the future of the NHS, including staffing and funding, if we are to deliver what we are capable of.

So, I hope that my optimism has enthused you, that you enjoy this edition, and that by taking the time to read this, your College journal, we have supported you, in some small way, in the process of continuous learning, with readable and practical articles that support your clinical practice.

\section{References}

1 Bolam H, Morton G, Kalra PR. Drug therapies in chronic heart failure: A focus on reduced ejection fraction. Clin Med 2018;18:138-45.

2 Byrne J and McCall D. One year's activity and outcome data from an ambulatory cardiology unit. Clin Med 2018;18:128-31.

3 Chatten K, Purssell H, Banerjee AK et al. Glasgow Blatchford Score and risk stratifications in acute upper gastrointestinal bleed: can we extend this to 2 for urgent outpatient management? Clin Med 2018;18:118-22.

4 Opio MO, Namujwiga T, Nakitende I et al. The prediction of inhospital mortality by mid-upper arm circumference: a prospective observational study of the association between mid-upper arm circumference and the outcome of acutely ill medical patients admitted to a resource-poor hospital in sub-Saharan Africa. Clin Med 2018:18:123-7.

Wing Commander Ed Nicol Editor-in-chief 